\title{
Construction of a dairy microbial genome catalog opens new perspectives for the metagenomic analysis of dairy fermented products
}

\author{
Mathieu Almeida 1,2,3,9, Agnès Hébert ${ }^{4}$, Anne-Laure Abraham ${ }^{1,2}$, Simon Rasmussen ${ }^{5}$, Christophe Monnet ${ }^{4,6}$, \\ Nicolas Pons ${ }^{3}$, Céline Delbès ${ }^{7}$, Valentin Loux ${ }^{8}$, Jean-Michel Batto ${ }^{3}$, Pierre Leonard ${ }^{3}$, Sean Kennedy ${ }^{3}$, \\ Stanislas Dusko Ehrlich ${ }^{3}$, Mihai Pop ${ }^{9}$, Marie-Christine Montel ${ }^{7}$, Françoise Irlinger ${ }^{4,6}$ and Pierre Renault ${ }^{1,2^{*}}$
}

\begin{abstract}
Background: Microbial communities of traditional cheeses are complex and insufficiently characterized. The origin, safety and functional role in cheese making of these microbial communities are still not well understood. Metagenomic analysis of these communities by high throughput shotgun sequencing is a promising approach to characterize their genomic and functional profiles. Such analyses, however, critically depend on the availability of appropriate reference genome databases against which the sequencing reads can be aligned.

Results: We built a reference genome catalog suitable for short read metagenomic analysis using a low-cost sequencing strategy. We selected 142 bacteria isolated from dairy products belonging to 137 different species and 67 genera, and succeeded to reconstruct the draft genome of 117 of them at a standard or high quality level, including isolates from the genera Kluyvera, Luteococcus and Marinilactibacillus, still missing from public database. To demonstrate the potential of this catalog, we analysed the microbial composition of the surface of two smear cheeses and one blue-veined cheese, and showed that a significant part of the microbiota of these traditional cheeses was composed of microorganisms newly sequenced in our study.

Conclusions: Our study provides data, which combined with publicly available genome references, represents the most expansive catalog to date of cheese-associated bacteria. Using this extended dairy catalog, we revealed the presence in traditional cheese of dominant microorganisms not deliberately inoculated, mainly Gram-negative genera such as Pseudoalteromonas haloplanktis or Psychrobacter immobilis, that may contribute to the characteristics of cheese produced through traditional methods.
\end{abstract}

Keywords: Genomic libraries, Genome sequencing, Sequence assembly, Next-generation sequencing, Comparative genomics, Metagenomics, Food bacteria, Dairy ecosystems

\section{Background}

Cheeses harbour a diverse microbial community, composed of a resident "house flora", that interacts with strains deliberately inoculated as starter or adjunct cultures [1-5]. The cheese microorganisms mainly consist of Firmicutes (lactic acid bacteria, staphylococci), Actinobacteria (coryneform bacteria), Proteobacteria, Bacteroidetes, yeasts and moulds. Their concentration in the final product sometimes exceeds

\footnotetext{
* Correspondence: pierre.renault@jouy.inra.fr

'Institut National de la Recherche Agronomique, UMR 1319 MICALIS, 78352 Jouy-en-Josas, France

${ }^{2}$ AgroParisTech, UMR MICALIS, 78352 Jouy-en-Josas, France

Full list of author information is available at the end of the article
}

$10^{10}$ cells per gram and it is generally accepted that most of them are cultivable in laboratory growth media [6-9]. An inventory of microorganisms with a history of use in food fermentations was established recently [10]. It contains 195 bacterial species (30 genera) and 71 yeast and mould species (35 genera). Among these bacterial species, only 80 (41\%) comprise at least one isolate for which a genome sequence isolated from food is available, with almost half of them within Lactobacillus species (NCBI database, May 2014). Furthermore, this list cannot be considered as exhaustive of the cheese microbial diversity, since occurrences of species previously undetected in milk and cheese are 
periodically reported [11-13] and isolates affiliated to novel taxa characterized [4]. Several species, such as Corynebacterium casei, Microbacterium gubbeenense, Arthrobacter arilaitensis, Arthrobacter bergerei, Agrococcus casei, Mycetocola reblochoni and Vibrio casei appear to be endemic in the cheese habitat and the environment of cheese manufacturing [14-17]. Environmental reservoirs of cheese microbial diversity such as milk, cow teat, human skin, brine baths, ripening room air, wooden vessels and shelves on which the cheese rests during ripening, have been identified, but their microorganism content remains largely uncharacterised $[18,19]$. Microbial communities of cheeses and dairy environments also represent largely unexplored reservoirs of genetic and metabolic diversity with potential beneficial use for fermented food production. An increase in the number of genome sequences of dairy bacteria is also useful for a better understanding of the genetic determinants involved in the adaptation to the dairy habitat and the generation of functional properties [20-23].

In recent years, high-throughput sequencing technologies and information technologies have allowed the development of new approaches for studying the genetic diversity of microbial communities. Among these, metagenomics is a powerful tool for assessing the phylogenetic diversity of complex microbial assemblages present in samples such as soil, sediment, food products or water [24] and for exploring the functional properties of their dominant populations. The characterization of metagenomic datasets relies on the use of reference databases that contain sequences of known origin and phenotype. Many of these studies are carried out by pyrosequencing of single target genes, such as $16 \mathrm{~S}$ rDNA sequences, that provide information restricted to the phylogenetic composition of the samples [25-31]. On the other hand, shotgun sequencing of whole community DNA provides additional information about the functions performed by the microbial community $[32,33]$. The length of the reads generated by current high throughput sequencing technologies is too short to allow accurate comparative analyses against distantly related genomes, thus requiring the availability of reference genomes closely related to organisms from the environment being studied. Currently, the international genome databases are biased towards model organisms and pathogens, and, according to Huson et al. [34], up to $90 \%$ of the sequences of a metagenomic dataset may remain unidentified due to the lack of adequate reference sequences. The sequencing of several hundred genomes is no longer a technical issue. However, this process still remains costly, mainly due to the cost of the construction of individual libraries for each genome being sequenced.

In the present study, we selected and sequenced 142 bacterial strains of dairy origin that belong to 137 different species and 67 genera. In order to exemplify the relevance of these new genomes to the understanding of food microbiota, we used the newly created catalog to analyse the microbiota of three cheese surfaces sequenced through whole metagenomic sequencing.

\section{Results}

Creation of a dairy reference genome catalog

After bibliographic investigation for bacterial species occurring in dairy products, we collected 142 dairy bacteria of various origins. The origin of the isolates and their taxonomy are shown in Additional file 1: Table S1. The collection comprised 36\% Gram negative bacteria, 35\% low GC Gram positive bacteria and 29\% high GC Gram positive bacteria. Among the 67 corresponding genera, four are genera for which no genome sequence was available in NCBI databases (May 2014 release): Kluyvera, Luteococcus, Marinilactibacillus, and Mycetocola. The distribution of the strains according to the type of dairy product and their geographic origin is shown in Figure 1.

We designed a low-cost library sequencing strategy, by pooling the bacterial genomes together in a controlled way prior to sequencing in order to reduce library construction costs. Unlike other approaches that rely on barcoding, we de-convolve the individual genomes by using a coabundance approach as described in Nielsen et al. [35] and Le Chatelier et al. [36] (see Additional file 2 supplementary document for an example of the clustering procedure). This strategy involves a two-step procedure, as follows. In the first step, the DNA of the 142 strains was mixed in five pools of about 30 strains each. To reduce the risk of chimeras each pool contained a mix of genomes from divergent genera (see Additional file 3: Table S2). The pools were sequenced using Illumina paired-end sequencing, and then assembled to produce five separate collections of contigs. In a second step, the genomes were redistributed into six pools of $\sim 90$ strains each, which were sequenced using SOLiD sequencing, and the resulting reads were mapped to the contigs generated in the first step in order to estimate the coverage of each contig within the stage 2 pools. We used SOLiD sequencing due to the availability of this platform at our institution and the lower cost of sequencing. However, other low-cost approaches for estimating the coverage of stage 1 contigs within the stage 2 pools could be used, such as, e.g., short runs on Illumina instruments. The resulting contig coverage matrix was then used to cluster together the contigs with correlated coverage profiles, each cluster corresponding to one of the original strains (see co-abundance clustering method section). The stage 1 pool assemblies contained each less than 20,000 contigs with a mean contig size of $40 \mathrm{kbp}$ (see Additional file 3: Table S2, Illumina assembly pool sheet). After the clustering procedure, more than $80 \%$ of the Illumina contigs comprising more than $96 \%$ of the total length of contigs could be attributed to individual strains. 
A

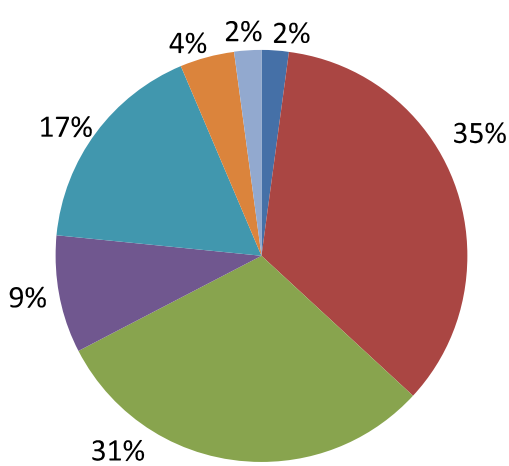

B

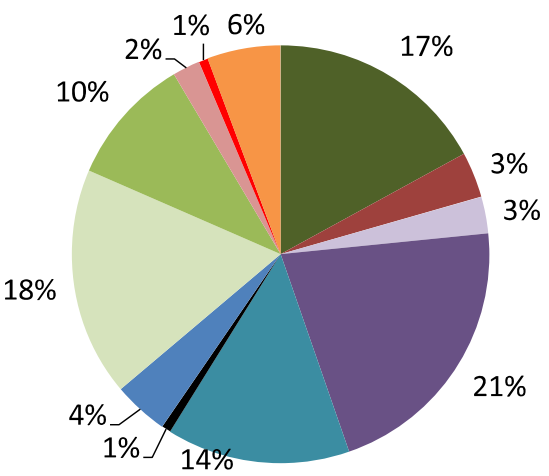

Fermented milk

- Soft smeared cheese

Milk

- Hard cheese

- Uncooked semi-hard cheese

Mould-soft cheese

Cheese without known technology

\author{
France: Alsace \\ France: Bourgogne \\ France: Jura \\ - France: Massif Central \\ - France: Normandie \\ - France: Nord \\ France: Savoie \\ France: Unknown region \\ Europe except France \\ Africa \\ America \\ Unknown
}

Figure 1 Origin of the 142 selected dairy bacterial isolates in function of the type of dairy product $(\mathrm{A})$ and the geographic area (B).

We assessed the quality of the clustering procedure by mapping the Illumina contigs to the closest NCBI genome sequences (using BLASTN [37], identity threshold $>=90 \%$ ). Furthermore, one organism in our collection - Arthrobacter arilaitensis Re117 - had already been sequenced and was added to one sequencing pool in order to validate the clustering procedure. We evaluated the correctness of contig clusters by computing two measures: the dominant genus the percentage of the contigs that could be mapped to related genomes belonging to the same genus as the organism represented by the cluster; and the reference coverage percentage of the total contig size of the pool that could be mapped to a genome from the dominant genus. We performed this analysis for the 53 draft genomes for which we could identify at least five genomes belonging to the same genus in the NCBI database. For these genomes, the mean dominant genus assignment and reference coverage percentage were of $97.7 \%$ and $89.5 \%$, respectively (see Additional file 4: Table S3). The dominant genus assignment indicated that only $2.3 \%$ of the total length of the genomes may have been mis-assigned by the clustering procedure. The reference coverage indicated that on average $10.5 \%$ of the length of each genome may be missing. The potentially missing information is likely present in the $4 \%$ of the fragments that were not assigned and contain mostly repeated sequences. We performed an optimized re-assembly procedure for each draft genome, in order to increase contig size and recover eventual missing parts of the genomes (see Methods section). Interestingly, the optimized re-assembly process halved the number of contigs and increased slightly the total contig size of genomes for which close references were available, such as genomes of the genera Leuconostoc and Streptococcus. In order to further assess the quality of the draft genomes (including those without near-neighbors in public databases), we relied on the six quality submission criteria established by the Human Microbiome Project (HMP) [38], plus two additional criteria that identify potential miss-assignment events during the clustering step: phylogenetic marker redundancy and tetranucleotide homogeneity. For the HMP draft genome quality criteria, 5 criteria correspond to contig and scaffold assembly length and coverage (see Methods section). The last HMP quality criteria checks the presence of 99 bacterial essential genes [39], which gives an indication of the proportion of the genome that has been assembled (see Method section for the threshold used and supplementary information for the additional criteria). The phylogenetic marker redundancy tests the redundancy of 40 protein markers expected to be conserved in all bacteria, not laterally transferable and not duplicated within a genome [40]. The tetranucleotide homogeneity tests the homogeneity of the tetranucleotide signature among all the contigs of a draft genome. 101 genomes passed the essential genes HMP criterion and the two additional criteria for 
mis-assignment detection, indicating that 101 genomes are almost complete with no mis-assignment evidence (see Additional file 4: Table S3, draft quality evaluation sheet). Among these, 72 passed all the quality criteria and were defined as high quality draft genomes. An example is the genome of Jeotgalicoccus psychrophilus CRBM D2, which was assembled in only 70 contigs and 20 scaffolds, and had a contig N50 size of $103 \mathrm{~kb}$. Sixteen additional assemblies presented incomplete sets of the HMP essential genes criterion but passed the two chimeric test criteria. For the 25 remaining draft genomes, 17 were too incomplete $(<1 \mathrm{Mb}$ in contig cumulative size) and 8 did not pass one of the two chimeric criteria. The genome of Arthrobacter arilaitensis Re117 [20], which was used in pool 1 as control for the procedure, passed all the HMP and chimeric criteria, and a comparison with the previously sequenced genome (Genbank project PRJNA53509) showed an average identity of $99.98 \%$, a completion level of $95.63 \%$ and the absence of improperly assigned contigs. The two plasmids present in this bacterium were also partially present in our draft. The missing sequences corresponded mainly to transposase regions which were not assembled possibly due to the assembly and clustering procedure which often has difficulties reconstructing repeated variable regions. In total 117 of the draft genome sequences (101 which passed all quality controls and an Additional 16 that had no evidence of chimeric contigs) were considered suitable for submission to public databases (see Additional file 1: Table S1). The 25 draft genomes with poor quality or possible contamination were not submitted to public databases, but were used in our project with caution for phylogenetic analyses.

From the 195 bacterial species or subspecies listed by Bourdichon et al. [10] to occur in food products, only 80 had at least one food isolate for which a genome sequence was available in the NCBI database (NCBI May 2014 release, see Additional file 5: Table S4). The present study provides genome sequences for 78 additional dairy isolates, which effectively doubles the number of available genome sequences of relevance to the study of fermented dairy products.

In order to better characterize the diversity of the bacterial strains studied here, we reconstructed their phylogenetic relationships. For that purpose, the genes corresponding to the 40 phylogenetic protein markers proposed by Mende et al. [40] were extracted from the 117 high quality draft genomes in order to build a phylogenetic tree (Figure 2). The tree shows that the selected bacterial isolates cover a large biodiversity. Four other trees were constructed (see Additional file 6: Figure S1, Additional file 7: Figure S2, Additional file 8: Figure S3 and Additional file 9: Figure S4) by inclusion of 328 genomic sequences from foodrelated bacteria or closely-related species (Bacteroidetes, Firmicutes, Actinobacteria and Proteobacteria) extracted from the NCBI database (see Additional file 10: Table S5, genome references for phylogeny sheet). The classifications of the genomes sequenced in the present study are consistent with the NCBI reference genomes, further confirming the correctness of our reconstruction. In some cases, for example for Alkalibacterium kapii, Marinilactibacillus psychrotolerans and Luteococcus japonicus, only distant NCBI reference genomes are available, highlighting the contribution of our study.

\section{Genomics of cheese bacteria}

The high quality draft sequences can be used to perform comparative genomic studies aimed at understanding the genetic underpinnings of the adaptation of bacteria to the food environment, e.g., through the characterization of metabolic pathways. Here we compared the genomes of strains from dairy and non-dairy environments for two genera. In a first example, we compared the genomic sequences of the four Arthrobacter strains isolated from cheese to that of 15 environmental isolates. Most bacteria of the genus Arthrobacter are isolated from environments such as soil, where they are considered to be ubiquitous [41]. Interestingly, the four cheese strains share several properties that may be linked to adaptation to the cheese habitat, such as a cluster of five genes involved in the catabolism of D-galactonate, as already described in Arthrobacter arilaitensis Re117 [20]. This gene cluster is absent from the genomes of the 15 Arthrobacter strains of environmental origin for which a sequence is available (see Additional file 11: Table S6). It has been hypothesized that D-galactonate may be produced by yeasts from lactose during the ripening of cheeses, and the ability to catabolize this compound could thus be beneficial for Arthrobacter strains in cheeses [20].

As a second example, we compared the genomes of two strains of Streptococcus infantarius isolated from Western African fermented milks, sequenced in this work (3AG and 11FA), with those of the type strain isolated from infant feces (ATCC BAA-102), and of strain CJ18, isolated from Eastern African fermented milk. The four strains contain each 1900-2000 genes and share 1567 genes. The strains could be divided into two groups, the two Western African strains, which displayed $99.7 \%$ identity on average within the shared genes (including 1206 fully identical genes), and the infant feces and the Eastern African strains, which displayed 99.3\% identity (including 485 fully identical genes) (see Additional file 12: Table S7). The strains of the two different groups displayed only $98.8 \%$ identity and fewer than 185 fully identical genes, confirming a clear separation between the Western African food strain and the two others. Further study of the gene content of the two Western African Streptococcus infantarius strains showed that these strains had acquired the ability to ferment lactose through the LacZS system, as previously 


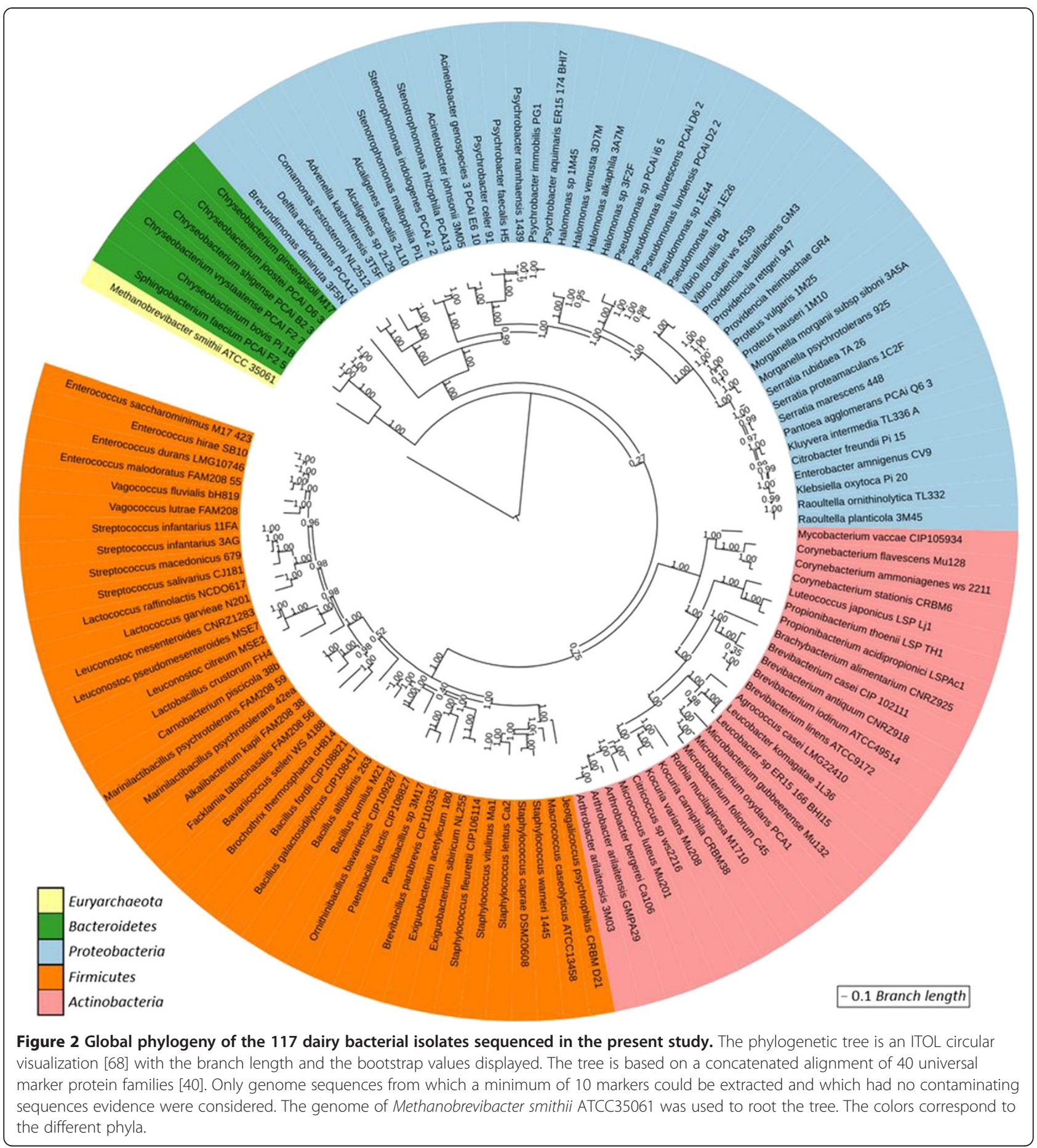

described for Eastern African strain CJ18 [42]. However, these genes are located within different regions of the chromosome and originate from a different donor. While lacZS may originate from S. thermophilus in the Eastern African CJ18 strain [43], it has probably been acquired from S. salivarius in the two Western Africa strains (see Additional file 13: Figure S5). These data show that adaptation of $S$. infantarius to the dairy fermentation niches occurred convergently and independently in these strains isolated respectively in Eastern and Western Africa.

\section{Application of the new genomic catalog to the metagenomic analysis of cheese microbiota}

Metagenomic analyses based on sequence mapping on a set of reference genomes can be used to identify and quantify genes and species [36]. To determine whether 
the addition of the new genome sequences to the 5873 publicly available genomes (bacteria, archaea, yeasts and moulds) could improve such analyses, we sequenced the microbial communities from the rind of three cheeses with protected designation of origin. These three cheeses were made from cow's milk and correspond to two soft smear-ripened cheeses ( $E$ and $L$ ), and one blue-veined cheese (G). Extracted DNA was sequenced by SOLiD technology and reads were assigned to species by mapping them to the reference microbial genomes and to the genome of Bos taurus (see Methods section).

The sequencing of the three samples provided from 8.4 to 15.5 million good quality reads (see Additional file 14: Table S8). The percentage of good quality reads mapping to the microbial reference genomes varied from $46.1 \%$ (cheese L) to 57.1\% (cheese E) (Figure 3). Interestingly, the reads that mapped only to the dairy genomes sequenced in the present study accounted for a large proportion of the good quality reads (from 16.7\% for cheese L to $23.7 \%$ for cheese G). In cheese G, $11.2 \%$ of the reads mapped to the Bos taurus genome (compared to $0.5 \%$ and $0.1 \%$ for cheeses $\mathrm{L}$ and $\mathrm{E}$, respectively). A deeper investigation of the cheese $\mathrm{E}$ good quality unmapped reads indicated that they may correspond to (i) strain specific genes belonging to the pan-genome (including prophages and mobile elements) and/or missing regions of the draft genomes, (ii) microorganisms for which genomes are still absent from the databases, (iii) distant genomic regions containing indels or more than 3 mismatches, which cannot be mapped with Bowtie. Lastly, 20\% of "technically good reads" on average are inherently un-mappable due to the characteristics of the SOLiD technology (this number is estimated from an analysis of the unmapped good quality read percentage in five different re-sequencing projects using the same sequencing and mapping techniques as in our paper, see Additional file 15: Table S9). The most prevalent microorganisms detected in the three cheeses are presented in Table 1 and a more detailed composition is shown in Additional file 14: Table S8.

In the smear-ripened cheese E, the Arthrobacter arilaitensis GMPA29 reference genome was the most represented, as it corresponded to $19.8 \%$ of the total good

\section{Cheese E}

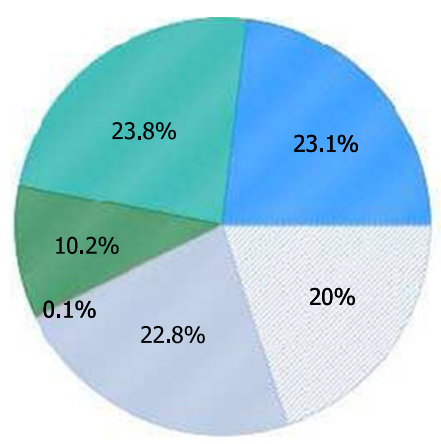

\section{Cheese G}

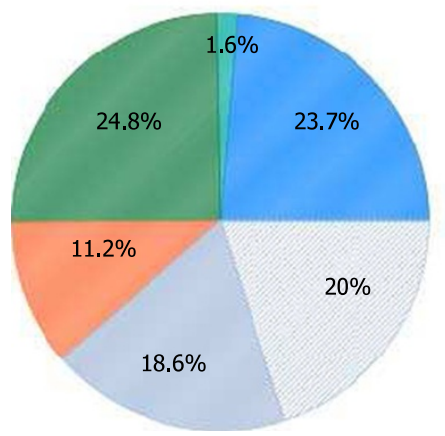

\section{Cheese L}

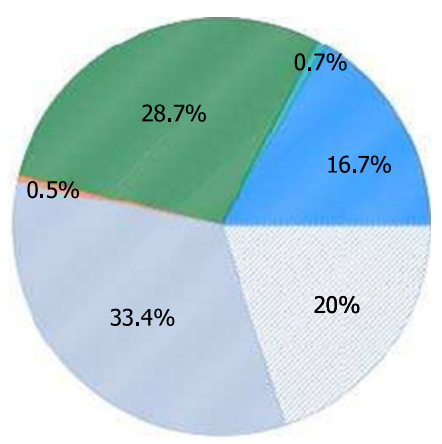

Reads mapped only on the new dairy genomes

Reads mapped only on NCBI genomes

Reads mapped on both databases

Reads mapped on Bos taurus

Unmapped good quality reads

Good quality reads potentially unmappable

Figure 3 Mapping of the good quality reads from the metagenomic sequencing of DNA from the surfaces of three cheeses. The good quality reads coming from 3 samples of cheese surface were aligned to 5873 genomes coming from NCBl and 117 genomes coming from our project. The repartition of the good quality reads that map only on the NCBI genomes (blue), on the genome sequenced in our project (green), on both NCBI and our genome (light green) and on Bos taurus genome (orange) is presented in pie charts. The unmapped good reads are presented in dark and light grey, respectively those lacking a reference and those potentially unmappable for technical reason. 
Table 1 Most prevalent microorganisms detected by metagenomic sequencing of three cheese surface samples

\begin{tabular}{|c|c|c|c|c|c|c|c|c|c|c|c|}
\hline & Reference genome & $\begin{array}{l}\text { New } \\
\text { (a) }\end{array}$ & $\begin{array}{l}\text { Commercial } \\
\text { cultures (b) }\end{array}$ & $\begin{array}{l}\text { Number of } \\
\text { reads (c) }\end{array}$ & $\begin{array}{r}\text { Number of } \\
\text { CDS (d) }\end{array}$ & $\begin{array}{l}\text { Cumulated } \\
\text { CDS length }\end{array}$ & $\begin{array}{r}\text { Covered } \\
\text { CDS (\%) (e) }\end{array}$ & $\begin{array}{r}\text { Covered } \\
\text { sequence length } \\
(\%)(f)\end{array}$ & $\begin{array}{r}\text { Mean } \\
\text { genome } \\
\text { coverage }\end{array}$ & $\begin{array}{r}\text { Mapped } \\
\text { reads }(\%)(g)\end{array}$ & $\begin{array}{r}\text { Sequences covered } \\
\text { by perfect match } \\
\text { reads }(\%)(\mathrm{h})\end{array}$ \\
\hline \multirow[t]{8}{*}{ Cheese E } & Arthrobacter arilaitensis GMPA29 & 1 & 1 & 2919327 & 3299 & 2875518 & 95.4 & 93.1 & 34.64 & 19.80 & 99.5 \\
\hline & Psychrobacter immobilis PG1 & 1 & 0 & 1259254 & 2941 & 2824830 & 99.4 & 94.3 & 15.48 & 8.54 & 99.9 \\
\hline & Vibrio litoralis B4 & 1 & 0 & 768119 & 3353 & 3158767 & 95.6 & 82.2 & 8.36 & 5.21 & 92.3 \\
\hline & $\begin{array}{l}\text { Pseudoalteromonas haloplanktis } \\
\text { TAC125 }\end{array}$ & 0 & 0 & 384444 & 3454 & 3327182 & 94.1 & 70.4 & 4.00 & 2.61 & 93.1 \\
\hline & Geotrichum candidum CLIB 918 & 0 & 1 & 378769 & 6925 & 10213537 & 98.3 & 38.6 & 1.30 & 2.57 & 95.5 \\
\hline & Halomonas sp. 1 M45 & 1 & 0 & 221008 & 3526 & 3281784 & 95.6 & 77.1 & 2.31 & 1.50 & 93.5 \\
\hline & $\begin{array}{l}\text { Lactococcus lactis subsp. lactis } \\
\|_{1403}\end{array}$ & 0 & 1 & 105179 & 2088 & 1869362 & 95.3 & 54.9 & 1.80 & 0.71 & 96.5 \\
\hline & Debaryomyces hansenii CBS767 & 0 & 1 & 77071 & 6295 & 9107395 & 91.7 & 16.6 & 0.30 & 1.27 & 85.6 \\
\hline \multirow[t]{8}{*}{ Cheese L } & $\begin{array}{l}\text { Pseudoalteromonas haloplanktis } \\
\text { TAC125 }\end{array}$ & 0 & 0 & 1434355 & 3454 & 3327182 & 93.7 & 89.5 & 14.95 & 17.03 & 97.6 \\
\hline & Halomonas sp. 1 M45 & 1 & 0 & 883652 & 3526 & 3281784 & 100.0 & 99.3 & 9.16 & 10.49 & 99.97 \\
\hline & Psychrobacter celer 91 & 1 & 0 & 146974 & 2584 & 2414775 & 95.6 & 76.5 & 2.08 & 1.74 & 91.5 \\
\hline & $\begin{array}{l}\text { Lactococcus lactis subsp. cremoris } \\
\text { A76 }\end{array}$ & 0 & 1 & 143400 & 2470 & 1969568 & 92.5 & 35.4 & 0.82 & 1.70 & 98.1 \\
\hline & Penicillium camemberti FM 013 & 0 & 1 & 83277 & 14611 & 22234696 & 85.1 & 10.8 & 0.13 & 0.99 & 97.7 \\
\hline & Vibrio litoralis B4 & 1 & 0 & 65937 & 3353 & 3158767 & 90.0 & 27.6 & 0.70 & 0.78 & 85.9 \\
\hline & Providencia heimbachae GR4 & 1 & 0 & 53280 & 3824 & 3516737 & 83.6 & 26.7 & 0.51 & 0.63 & 55.3 \\
\hline & Geotrichum candidum CLIB 918 & 0 & 1 & 45165 & 6925 & 10213537 & 95.0 & 12.7 & 0.15 & 0.54 & 95 \\
\hline \multirow[t]{6}{*}{ Cheese G } & Arthrobacter bergerei Ca106 & 1 & 1 & 2878361 & 3553 & 3110335 & 98.6 & 95.7 & 31.77 & 18.58 & 99.2 \\
\hline & $\begin{array}{l}\text { Lactobacillus delbrueckii subsp. } \\
\text { bulgaricus ATCC11842 }\end{array}$ & 0 & 1 & 1179878 & 1508 & 1340406 & 98.7 & 95.4 & 29.44 & 7.62 & 99.8 \\
\hline & Penicillium camemberti FM 013 & 0 & 1 & 633123 & 14611 & 22234696 & 99.4 & 54.2 & 1.00 & 4.09 & 96.5 \\
\hline & $\begin{array}{l}\text { Streptococcus thermophilus LMG } \\
18311\end{array}$ & 0 & 1 & 597916 & 1827 & 1462709 & 98.3 & 86.1 & 13.62 & 3.86 & 99.4 \\
\hline & Penicillium roqueforti FM 164 & 0 & 1 & 254435 & 12630 & 23447373 & 98.5 & 26.3 & 0.38 & 1.64 & 98.4 \\
\hline & $\begin{array}{l}\text { Pseudoalteromonas haloplanktis } \\
\text { TAC125 }\end{array}$ & 0 & 0 & 146457 & 3454 & 3327182 & 93.5 & 57.8 & 1.53 & 0.95 & 92.3 \\
\hline
\end{tabular}


Table 1 Most prevalent microorganisms detected by metagenomic sequencing of three cheese surface samples (Continued)

\begin{tabular}{|c|c|c|c|c|c|c|c|c|c|c|}
\hline Debaryomyces hansenii CBS767 & 0 & 1 & 80179 & 6295 & 9107395 & 94.2 & 17.6 & 0.31 & 0.52 & 97.1 \\
\hline $\begin{array}{l}\text { Psychrobacter aquimaris ER15 } 174 \\
\text { BHI7 }\end{array}$ & 1 & 0 & 74153 & 2830 & 2734881 & 93.7 & 41.7 & 0.87 & 0.48 & 1.5 \\
\hline
\end{tabular}

(a) Genomes sequenced in the present study (1) or from the NCBI database (0).

(b) Species known to be components of cheese making commercial cultures.

(c) Number of reads mapped on CDS from the reference genome with three or less mismatches on 35 nucleotides.

(d) Number of CDS in the genome. CDS corresponding to insertion sequences, prophages and potential repeated and transferable elements were removed.

(e) Percentage of CDS covered with at least one read.

(f) Percentage of sequence covered by at least one read (sequence is restrained to the selected CDS).

(g) Number of reads aligned with this genome divided by the number of good quality reads.

(h) Length of sequence covered by perfect match reads (with no mismatch on the $35 \mathrm{nt}$ length alignment) divided by the length of the sequence covered by reads.

For each cheese, the data presented correspond to the eight reference genomes with the highest numbers of mapped reads. 
quality reads, followed by Psychrobacter immobilis PG1 and Vibrio litoralis B4, with 8.5 and $5.2 \%$ of the reads, respectively. Furthermore, between 95.4 and $99.4 \%$ of their coding sequences were detected, with a high level of coverage (from 8.4X to 34.6X). The genomes of Arthrobacter arilaitensis GMPA29 and Psychrobacter immobilis PG1 are almost entirely covered (from 99.5 to 99.9\% of the reference size), showing that the detected strains were closely related to the reference strains. The reference strain Psychrobacter immobilis PG1 was isolated from the dairy plant that produces the smear-ripened cheese E, but two years earlier. The high proportion of perfect matches with reference strain PG1 may thus be explained by the presence of an offspring of this strain in cheese E. Many reads were also assigned to the genomes of the yeasts Geotrichum candidum CLIB 918 and Debaryomyces hansenii CBS767.

In the second smear-ripened cheese (cheese L), Pseudoalteromonas haloplanktis TAC125, Halomonas sp. 1 M45 and Psychrobacter celer 91 were the three dominant reference bacteria, with $17.0 \%, 10.5 \%$ and $1.7 \%$ of the good quality matches, respectively. In this cheese sample, the sequences of the reads mapped to Halomonas sp. 1 M45 were essentially perfect matches ( $>99.9 \%$ of covered positions with $99.9 \%$ perfect match reads, coverage of $9.2 \mathrm{X}$ ). These data suggest that the Halomonas strains present in the cheese sample are almost identical to the reference strain. However, even though the reference strain 1 M45 has also been isolated from a smear-ripened cheese of the same protected designation of origin, it originated from another manufacturing plant. More than fifty thousand reads were assigned to Providencia heimbachae GR4. However, only $55.3 \%$ of covered positions of this reference strain are without mismatch, which indicates that the strain present in the cheese sample is not closely related to the reference strain, and may even correspond to another species. Surprisingly, more than 80 thousand reads $(\sim 1 \%$ of the total good quality reads in cheese L) mapped to the Penicillium camemberti FM 013 genome, with $97.7 \%$ of perfect match reads, even though this species is not known to occur in smear-ripened cheeses. One may hypothesize that this could result from cross-contamination due to the manufacturing of mould-ripened cheese in the same plant.

The surface of the blue-veined cheese $\mathrm{G}$ was dominated by a strain close to Arthrobacter bergerei Ca106 (18.6\% of the reads, $99.2 \%$ perfect match reads). Like for the two other cheeses, Psychrobacter species seem to be present in this cheese. Cheese $\mathrm{G}$ was probably manufactured with a thermophilic lactic starter culture, since Streptococcus thermophilus and Lactobacillus delbrueckii species were the dominant lactic acid bacteria, in contrast to the two other cheeses, in which Lactococcus lactis was the dominant lactic acid bacterium. Strains related to other reference strains sequenced in the present study, such as Psychrobacter aquimaris, Brachybacterium tyrofermentans, Corynebacterium ammoniagenes, Brevibacterium antiquum, Microbacterium gubbeenense, Brochothrix thermosphacta and Marinilactibacillus psychrotolerans, were also present in the cheeses ( $>80 \%$ perfect match reads, see Additional file 14: Table S8). Interestingly, among the eight most prevalent microorganisms detected in each cheese by metagenomic analysis, two (cheese G), four (cheese E) or five (cheese L) corresponded to species or genera of gramnegative bacteria which are not known components of cheesemaking commercial cultures (Table 1).

\section{Discussion}

In the present work, we produced 137 draft genomes isolated from dairy products, which almost doubled the number of different species isolated from fermented dairy products. This genome catalog was realized using a lowcost library sequencing strategy based on a combinatorial pooling approach in which a reduced number of DNA pools were sequenced. Pooling strategies have been previously been used to reduce costs for BAC sequencing [44]. Here we rely on a co-abundance clustering approach that we developed for reconstructing genomes directly from metagenomic samples [35]. In the present pooled approach, only 11 libraries were required to produce 150 draft genomes, leading to a cost of $\sim 200$ USD per genome as opposed to $\sim 500$ USD if each genome were sequenced separately (using best commercial offers available in 2011). Today, this price differential may be even higher as library construction costs have not decreased as much as sequencing costs. This cost savings comes with some limitations. First, we suggest that only distant genomes (i.e. from different genera at least) should be mixed and sequenced together to optimize the assembly and clustering steps. Second, several genomes were poorly sequenced, however most of them were high GC\% draft genome, known to be difficult to sequence using Illumina sequencing [45]. Also, about $4 \%$ of the total sequence length could not be assigned to an individual strain and we estimated that on average $2 \%$ of a genome's sequence may be mis-assigned due to limitations of the clustering approach. However, an examination of unassigned fragments $>2 \mathrm{~kb}$ showed that they correspond mainly to mobile elements (plasmids and phages) while genome data curation showed that potentially mis-assigned fragments are generally $<1 \mathrm{~kb}$, and primarily impact genomes of lower quality. This fact prompts us to suggest that the use of these drafts for comparative genomics should be restricted to high quality draft genomes and to genes present in long contigs or scaffolds (i.e. bigger than $1 \mathrm{~kb}$ ). Lastly, the bioinformatics analysis pipeline is more complex to set up than simple assembly procedure in single genome sequencing. Despite these limitations, 117 of the 142 sequenced genomes resulted in good or high quality draft genomes suitable for submission 
to public database. Some of the remaining 25 genomes may still be useful as references for metagenomic analyses.

The microbial composition of the surfaces of three cheeses was investigated by high throughput metagenomic profiling. As all the DNA present in the cheese samples is sequenced, the high throughput sequencing may detect any type of DNA (bacteria, archaea, eukaryotes and viruses), provided that adequate references are used. Eukaryotes, such as Geotrichum candidum, Debaryomyces hansenii, and Penicillium roqueforti, were found, which was not surprising, as these fungi are frequently used in cheesemaking. Interestingly, many reads from cheese G mapped on the Bos taurus genome. We hypothesize that this is due to the presence of cow somatic cells in the milk used for the manufacturing of cheese G. The impact of milk somatic cells on the ripening of cheeses has been shown in several studies as associated to the flock health $[46,47]$.

Shotgun sequencing allows a relative quantification of DNA molecules present in a sample, based on counting the number of reads mapped to each member of the community. High throughput sequencing allows higher resolution quantitation and we have shown that we can recover even fairly minor taxonomi groups, such as the Leuconostoc genus (see Additional file 14: Table S8), known to be part of the minority population in cheeses [48]. However, additional experiments may be needed to validate the identification and quantitation of low abundance populations.

Presence or absence of complete set of genes or of specific genes, and their level of sequence homology allows also confirming characteristics of particular strains. For example, cheeses $\mathrm{E}$ and $\mathrm{L}$ metagenomic profiles indicated the presence of strains closely related, respectively, to Psychrobacter immobilis PG1 and Halomonas sp. 1 M45 coming from our catalog. Since these reference strains were isolated in the same cheese factory several years earlier for the former and in the same DOP from another factory for the later, our analysis would reflect the setting up of strains sharing common origins with the references in these cheeses. Metagenomic profiling provides thus new perspectives to study cheese ecology by tracing genomes or genes, which should allow pointing out particular strains (e.g. starters, potential "terroir" or regional strains, contaminants...), and following their dissemination and development during cheese processes.

The metagenomic profiling of the surfaces of the three cheeses confirmed that microorganisms that are not deliberately inoculated constitute a large part of the microbiota, appearing among the few dominant species in cheese rind. For example, they are predominant in cheese L. Several of the corresponding microorganisms, such as Pseudoalteromonas, Halomonas, Vibrio, Marinilactibacillus and Psychrobacter are Gram-negative bacteria which had been previously detected in such cheeses $[1,2,9,12,13,28,49-53]$, and also in a recent large amplicon sequencing study of the microbial composition of 137 different cheese rinds [33]. They may originate from the environment of cheese manufacturing (brine, tools, surfaces of shelves ...), and their high abundance suggests that they may have an impact on the properties of the final product. As the analysed cheeses were marketed and were of very good quality, these microorganisms cannot be considered here as spoilers.

\section{Conclusion}

The genomes sequenced in the present study considerably increased the numbers of mapped reads, although a significant proportion of the metagenomic reads remained unassigned ( $20 \%$ once taken into account unmapped reads inherent to $\mathrm{SOLiD}$ technology). These data indicate that even if more than 6000 genomes are currently available in public databases (including the genomes we generated here), additional microorganisms found in traditional cheeses are still missing from this reference collection. Further studies are necessary to complete this reference in order to provide a complete view of the cheese ecosystem. To our surprise, collecting the present reference strain set constituted a laborious work, since strains corresponding to non-starter species are frequently not conserved once described. We anticipate that the results of this work will motivate isolation and conservation of new reference strains, as well as independent isolates of the same species to support safety assessment, establish biodiversity resource and strain specificity in products. Direct sequencing and assembly as performed for the human microbiome could also provide new potential references [36], although this procedure is significantly more expensive. In summary, the present study considerably extended the effectiveness of shotgun metagenomic analysis of cheese microbiota. Even if such analyses require generating and computing large amounts of sequencing data, the technologies are evolving rapidly and one may anticipate that in the future, they will become routine in the investigation of food microbiota.

\section{Methods}

\section{Bacterial isolates and growth conditions}

The bacterial isolates working collection was composed of 142 isolates originating from milk, fermented milks, and cheeses, and five food isolates that were not of dairy origin (see Additional file 1: Table S1).

\section{DNA extraction from liquid cultures of bacterial isolates}

After cultivation, bacterial cells were harvested by centrifugation for $10 \mathrm{~min}$ at $12,000 \times g$ and approximately $100 \mathrm{mg}$ of cell pellet were suspended in $400 \mu \mathrm{l}$ of buffer (0.4 M NaCl, 2 mM EDTA, 10 mM Tris- $\mathrm{HCl}, \mathrm{pH}$ 8). 
For gram-positive bacteria, an enzymatic lysis step was performed by incubating the cells for 1 hour at $37^{\circ} \mathrm{C}$ after addition of $50 \mu \mathrm{l}$ of lysozyme $(20 \mathrm{mg} / \mathrm{ml})$ for Actinobacteria strains or of $50 \mu \mathrm{l}$ of lysostaphin (100 Units) for Staphylococcus strains. One hundred microliters of SDS (20\%) and $40 \mu \mathrm{l}$ of proteinase $\mathrm{K}(15 \mathrm{mg} / \mathrm{ml})$ were then added and the mixture was subsequently incubated for 1 hour at $55^{\circ} \mathrm{C}$. One hundred and fifty $\mathrm{mg}$ of $0.1 \mathrm{~mm}$ diameter zirconium beads (Biospec Products, Bartlesville, OK, USA), $150 \mathrm{mg}$ of $0.5 \mathrm{~mm}$-diameter beads and $500 \mu \mathrm{l}$ of phenol/chloroform/isoamylic alcohol (25/24/1; pH 8) were added to the tube, which was vigorously shaken in a bead-beater (FastPrep-24 instrument; MP Biomedicals Europe, Illkirch, France) for $45 \mathrm{~s}$ at a speed of $6.0 \mathrm{~m} / \mathrm{s}$. The sample was centrifuged $(45 \mathrm{~min}$ at $12,000 \times \mathrm{g}$ ) and the upper phase was transferred in a Phase Lock Gelheavy tube (Eppendorf, Hamburg, Germany) and mixed with $500 \mu \mathrm{l}$ of phenol/chloroform/isoamylic alcohol. After centrifugation $(15 \mathrm{~min}$ at $12,000 \times g)$, the upper phase was mixed with $500 \mu \mathrm{l}$ of chloroform and centrifuged (15 min at $12,000 \times g)$. DNA was precipitated overnight at $-20^{\circ} \mathrm{C}$ after addition of 0.1 volume of $3 \mathrm{M}$ sodium acetate and 2 volumes of cold absolute ethanol to the upper phase. After centrifugation $(30 \mathrm{~min}$ at $12,000 \times g)$, the DNA pellet was washed with $70 \%$ ethanol and resuspended in $1 \mathrm{X}$ TE buffer. Two microliters of RNase solution $(10 \mathrm{mg} / \mathrm{ml})$ were added and the mixture was subsequently incubated for $30 \mathrm{~min}$ at $37^{\circ} \mathrm{C}$. The concentration and quality of genomic DNA was evaluated using a NanoDrop ND-1000 spectrophotometer (NanoDrop Technology Inc., Wilmington, DE, USA). Moreover DNA $(5 \mu \mathrm{L})$ was loaded on a $1 \%$ agarose gel and visualized after migration by ethidium bromide staining.

\section{Sequencing of rrs and rpoB genes from bacterial isolates}

The species corresponding to each genome was confirmed by sequencing the $16 \mathrm{~S}$ rRNA or the $r p o B$ gene (see Additional file 1: Table S1). The rrs gene (encoding the $16 \mathrm{~S}$ rRNA) was amplified with primers $\mathrm{pA}\left(5^{\prime}-\right.$ AGAGTTTGATCCTGGCTCAG-3') and pH (5' ${ }^{\prime}$ AAG GAGGTGATCCAGCCGCA-3'), as previously described [54]. Since the rrs gene is not always sufficient to distinguish closely related species, especially Enterobacteriaceae, the housekeeping gene rpoB (encoding the beta chain of the DNA-directed RNA polymerase), that has been shown to resolve phylogenetic relationships in various bacterial groups [55], was also used. PCR amplification of $r p o B$ was performed with primers VIC4 $\left(5^{\prime}\right.$ GGCGAAATGGCDGARAACCA-3') and VIC6 (5' GARTCYTCGAAGTGGTAACC-3') [56]. Both strands of the resulting amplicons were sequenced by GATC Biotech (Konstanz, Germany), using the same primers than for the PCR amplifications. The sequences were then assembled using the CAP3 program [57] and compared to the GenBank database using the Basic Local Alignment Search Tool (BLAST) [37] to determine the closest known relatives of the rrs or $r p o B$ gene sequences.

\section{Genome sequencing}

The 147 bacteria DNA samples were distributed in equivalent amounts $(0.3 \mu \mathrm{g})$ in five metagenomic pools containing each about 30 genomes. Only different genera were mixed together in a single pool to improve the assembly process by reducing the presence of possible identical regions (see the Additional file 2 supplementary information document). Each pool was sequenced using the Illumina HiSeq 2000 system, with around 90 million paired-end reads of 91 nucleotides in length, an insert size of $\sim 350 \mathrm{bp}$ for pool 1 and $\sim 310 \mathrm{bp}$ for the four other pools. Low quality reads (with 3 or more " $N$ "), which constituted less than $8 \%$ of the total reads, were discarded. The assembly was performed for the five metagenomic pools independently, using SOAPdenovo (v1.04) [58]. Kmer size was selected separately for each pool by evaluating the best contig size, $\mathrm{N} 50$ and N90, and the best percentage of reads re-mapped to the assembly (see Additional file 3: Table S2, Illumina assembly sheet). Only contigs of $100 \mathrm{bp}$ in length or more were kept for further analysis. The draft genomes are available under the pending BioProject ID PRJEB230 to PRJEB363 (see Additional file 1: Table S1).

\section{Co-variance clustering}

To assign the contigs to their original genomes, we used a clustering method based on the co-variance principle, derived from method described by Nielsen et al. [35] and Le Chatelier et al. [59] (see the Additional file 2, supplementary information). For this purpose, six new DNA pools were created by mixing genomic DNA so that each DNA sample has a different combination in the pools, and therefore each genome has a unique presence signature (see Additional file 3: Table S2, composition pool sheet). The six new DNA pools were sequenced using SOLiD technology 4, with around 90 million single reads in each pool of 50 nucleotide length. The SOLiD reads were aligned to the five Illumina contigs using the Bowtie aligner [60] (see Additional file 3: Table S2, SOLiD mapping data sheet). This resulted in the creation of five independent contig coverage matrix, used for the clustering process. This alignment allows calculating a coverage vector for each contig, corresponding to the presence and absence of the contig in the 6 combinatorial pools. The contig coverage vectors are compared to the strain presence and absence in the 6 combinatorial pools, using the Pearson correlation coefficient. The contigs are assigned to the strain with which they share the highest Pearson correlation, as long as the correlation value is equal to or higher than 0.95. The Illumina and SOLiD samples are 
accessible under the project ID PRJEB6314 at the SRA database.

\section{Genes and contigs taxonomical annotation}

All contigs were taxonomically annotated by sequence similarity using BLASTN to a database containing 1411 reference genomes (extracted from NCBI database, June 2012 version). Sequence similarity $>=90 \%$ on at least 100 nucleotide was used for genus level annotation. This taxonomical assignment was used to calculate the dominant genus assignment and the reference coverage of the clustering, by considering the 53 strains with at least 5 different species present in the NCBI database. This restriction was made in order to reduce the likelihood of incorrect assignments by the BLASTN procedure (see Additional file 4: Table S3, cluster BLASTN assignation sheet). The unassigned contigs were considered as part of the dominant genus assignment, to differentiate them from the contigs assigned to a different genus which represent a potential mis-assignment from the clustering step. The 11 clusters with less than $500 \mathrm{~kb}$ in total contig size were not considered for the dominant genus assignment and reference coverage due to their low quality and high level of fragmentation.

\section{Optimize re-assembly of draft genomes and quality evaluation}

To increase the size of contigs and scaffolds, we performed an optimized de novo re-assembly procedure after the clustering procedure. The contig pools were used to recruit reads from their Illumina HiSeq 2000 sequencing pool, by alignment to the contigs using BWA [61]. The recruited reads were corrected using Quake [62]. A new de novo assembly was performed for each cluster using only the reads that were remapped on them, using Velvet [63]. Scaffold gaps were filled using SOAPdenovo GAPCloser [58]. When a close species reference genome was available in the NCBI database, we used it for an assisted assembly procedure. This procedure used the NCBI contigs in combination with the cluster contigs to recruit the reads. This may recover the missing regions that were lost during the first assembly and clustering procedures. Reconstructed genome drafts were classified from low to high quality by using the Human Microbiome Project assembly criteria [64]. The threshold used for each HMP criteria validation are: (1) contig N90 > = $500 \mathrm{bp}$; (2) $90 \%$ or more of the 99 bacterial essential genes are found; (3) $90 \%$ or more of the bases in the assembly have more than 5 fold sequence coverage; (4) contig N50 > = $5 \mathrm{~kb}$; (5) scaffold N50 >= $20 \mathrm{~kb}$; (6) average contig length $>=5 \mathrm{~kb}$. Two other additional criteria for chimera detection were computed: the tetranucleotide homogeneity score and function redundancy (see Additional file 4: Table S3, draft genome quality sheet; and the supplementary information document). The tetranucleotide homogeneity was calculated by counting the number of different tetranucleotides in all contigs, divided by the size of the contigs, to produce a tetranucleotide frequency vector. Each tetranucleotide frequency vectors were compared using the Spearman rho correlation, and the mean rho correlation value of all pairwise Spearman correlation comparison was calculated. The draft were considered as potentially contaminated by another draft when the mean Spearman rho was lower than 0.6 . The 40 marker protein redundancy was calculated by first searching for the marker protein in the draft as described in the Genome annotation and phylogeny annotation procedure section. Then each protein detected at least twice was listed in all drafts. A draft was considered as chimeric if 3 or more markers were redundant.

\section{Genome annotation and phylogeny annotation procedure} RAST (Rapid Annotation using Subsystem Technology) was used for annotating the genome drafts in the SEED environment [65]. Genomic drafts passing the core-ratio HMP criterion and 328 NCBI reference genomes were used for phylogenic classification (see Additional file 10: Table S5, genome references phylogeny sheet). For each draft, 40 markers commonly used for phylogeny classification and corresponding to 40 essential proteins [40], were detected using BLASTP procedure and a marker reference database of about 1500 complete genomes. The best hit was selected with at least $50 \%$ identity and $50 \%$ coverage. Each marker protein was aligned to reference markers using MUSCLE [66] and the 40 individual alignments were concatenated to a single alignment. The missing markers were replaced by gapped lines, not used for the distance calculation. Only the drafts with at least 10 markers out of the 40 described above were selected for the tree. The tree was constructed using FastTree [67] with the parameters: -gamma -pseudo -spr 4 -mlacc 3 -slownni. The visualization was done using ITOL [68], in circular mode view and branch length displayed mode.

\section{Extraction of DNA from cheese samples}

For each of the three types of cheeses, five pieces of rind ( $8 \mathrm{~cm}^{2}$; mean thickness: $\sim 5 \mathrm{~mm}$ ) were taken using a circular punch (3.2 cm in diameter) and a knife, mixed together, and cut in small pieces. Twenty grams of cheese rind were then mixed with $20 \mathrm{ml}$ of guanidium thiocyanate $(4 \mathrm{M})$ in Tris- $\mathrm{HCl}(\mathrm{pH} 7.5,0.1 \mathrm{M})$ and dispersed with a mechanical blender (Ultra-Turrax ${ }^{\circ}$ model T25; Ika Labortechnik, Staufen, Germany) for $3 \mathrm{~min}$ at 14,000 rpm. After adding $2.4 \mathrm{ml}$ of sodium laurylsarcosinate $(100 \mathrm{~g} / \mathrm{l})$ and gentle mixing for $1 \mathrm{~min}$, five $1.9 \mathrm{ml}$-aliquots were added to five 2$\mathrm{ml}$ tubes containing $350 \mathrm{mg}$ of zirconium beads $(0.1-\mathrm{mm}$ diameter; Sigma, St-Quentin-Fallavier, France) and the tubes were centrifuged for $10 \mathrm{~min}$ at $20,800 \mathrm{~g}$ and $4{ }^{\circ} \mathrm{C}$. 
The supernatants, which included the fat layer, were removed, and the tubes were frozen at $-20^{\circ} \mathrm{C}$. After thawing, $600 \mu \mathrm{l}$ of Tris-EDTA buffer $(\mathrm{pH} 8.0 ; 100 \mathrm{mM}$ Tris, $10 \mathrm{mM}$ EDTA), $40 \mu \mathrm{L}$ of proteinase $\mathrm{K}(15 \mathrm{mg} / \mathrm{ml}$; Sigma, St Quentin Fallavier, France) and $100 \mu \mathrm{l}$ of sodium dodecyl sulfate $(200 \mathrm{~g} / \mathrm{l})$ were added to the tubes, which were then vortexed for $2 \mathrm{~min}$, and subsequently incubated for $2 \mathrm{~h}$ at $55^{\circ} \mathrm{C}$. After cooling on ice, the tubes were vigorously shaken for $40 \mathrm{~s}$ in a bead beater (FastPrep ${ }^{-} 2$ System; MP Biomedicals, Illkirch, France) at a speed of $4.0 \mathrm{~m} / \mathrm{s} .700 \mu \mathrm{l}$ of phenol were then added and the content of the tubes was gently mixed for $1 \mathrm{~min}$. The tubes were centrifuged for $5 \mathrm{~min}$ at $20,800 \mathrm{~g}$ and $20^{\circ} \mathrm{C}$ and the aqueous phases were transferred to 2-ml tubes containing a gel that improves separation between the aqueous and organic phases (Phase Lock Gel $^{\mathrm{TM}}$ Heavy; Eppendorf, Germany). After adding $700 \mu \mathrm{l}$ of phenol-chloroform-isoamyl alcohol (25:24:1; saturated with $10 \mathrm{mM}$ Tris, pH 8.0, $1 \mathrm{mM}$ EDTA) and gentle mixing for $1 \mathrm{~min}$, another centrifugation was performed for $5 \mathrm{~min}$ at $20,800 \mathrm{~g}$ and $20^{\circ} \mathrm{C}$ and the aqueous phases were transferred in new Phase Lock Gel ${ }^{\mathrm{Tm}}$ tubes. Another extraction with $700 \mu$ l of phenol-chloroform-isoamyl alcohol was then performed, and the aqueous phases were recovered in a 2-ml centrifugation tube, mixed with $5 \mu \mathrm{l}$ of RNase A (20 mg/ml, Sigma), and incubated for $1 \mathrm{~h}$ at $37^{\circ} \mathrm{C}$. The DNA was then precipitated by adding $1 \mathrm{ml}$ of isopropanol and $50 \mu \mathrm{l}$ of sodium chloride $(5 \mathrm{M})$ and incubating the tubes overnight at $-20^{\circ} \mathrm{C}$. The DNA was recovered by centrifugation for $10 \mathrm{~min}$ at $20,800 \mathrm{~g}$ and $4^{\circ} \mathrm{C}$, and the pellets were subsequently washed three times with $1 \mathrm{ml}$ of $70 \%$ ( vol/vol) ethanol. They were then dried for $30 \mathrm{~min}$ at $42^{\circ} \mathrm{C}$ and dissolved in $50 \mu \mathrm{l}$ of water, after which the five samples corresponding to the same cheese were pooled together.

\section{Metagenomic sample mapping}

Three DNA samples from cheeses were sequenced using SOLiD technology, which yielded between 11 and 19 million single reads of 50 nucleotides length. The identification of species was done in two steps: a first mapping was done on a catalog reference of 5990 genomes, which included the 117 draft sequenced in the present study, and a second mapping with more detailed analyses on a selection of genomes (see Additional file 10: Table S5, genomes metagenomic analyse sheet). The first mapping was performed using Bowtie aligner [60] (with parameters: first 35 nucleotides mapped; 3 mismatches allowed; 10000 matches by read allowed), on the whole database. This mapping allowed a first selection of genomes. Genomes with no annotation were cut into fragments of 1000 bases. Genomes with less than 20\% of genes (or less than $20 \%$ of fragments) covered by reads were removed. For species expected to be in food microbiota, several reference genomes were chosen. Otherwise, one genome was selected for each species. When possible, genomes with annotations were selected in priority. The samples were then mapped against the selected genomes (59 for cheese E, 86 for cheese L, 67 for cheese G; see Additional file 10: Table S5, sheet genomes metagenomic analysis) with Bowtie aligner (same parameters, and the best -strata option). A first analysis was done to explain the unmapped reads. The distribution of the mean quality of the reads for the cheese sample was evaluated for the mapped reads (see Additional file 16: Figure S6). The mean quality of the mapped reads was higher than 20 for more than $95 \%$ of the reads. Considering this, reads with a mean quality under the value of 20 were considered as "bad quality reads" and not considered for the metagenomic analyses. Unmapped good quality reads were then mapped on Bos taurus genomes with Bowtie (same parameters). Finally, an analysis of the unmapped good quality read percentage was performed using the same SOLiD technology (SOLiD v4) and the same read mapper (Bowtie) than the cheese analysis with a set of five bacterial genome re-sequencing projects (see Additional file 15: Table S9). While in this experiment $100 \%$ of the good quality reads should have mapped with their reference genome, only $80 \%$ of the good quality reads did, possibly due to sequencing errors in the reads.

Finally, genomes present in samples were identified from the second mapping results. Genomic regions that were less informative and/or that could have been acquired by gene transfer (intergenic regions, tRNA, rRNA, genes annotated as "transposase", "integrase", "IS", "phage/ prophage" or "plasmids") were removed. We then quantified the percentage of the genome covered by at least one read, and the percentage of the genes covered by at least one read. A first filter was done by removing genomes to which less than 700 reads mapped and genomes with less than $20 \%$ of coding DNA sequences covered by at least one read. In order to estimate if the reads were evenly mapped across the genome, we computed the average number of reads per coding DNA sequences. (number of reads / number of coding DNA sequences). If the average number was $>=10$ and the observed percentage of coding DNA sequences covered by reads $>80 \%$ or the average number between 2 and 10 and the observed percentage of coding DNA sequences covered by reads $>70 \%$, we considered the species to be present in the cheese. Finally, as reads were allowed to map several genomes, some reads could map to several reference genomes of the same species even when only one strain of this species is present in the sample. Therefore, to get more stringent results, only one reference genome was kept for each species or subspecies (the genome with the highest percentage of coding DNA sequences covered by reads). The relative abundances of the different genomes were calculated by dividing the number of reads assigned to each genome by the 
number of good quality reads. The raw SOLiD and Illumina read data for all samples has been deposited in the European Bioinformatics Institute (EBI) European Nucleotide Archive (ENA) under the accession number PRJEB6314.

\section{Additional files}

\author{
Additional file 1: Table S1. Origin and taxonomy of the bacterial \\ isolates.
}

Additional file 2: Supplementary information document. This supplementary information document details the genome assembly steps, from sequencing to the quality evaluation.

Additional file 3: Table S2. Establishment of the sequencing pools. Additional file 4: Table S3. Evaluation of the genome clustering procedure and the quality of the genome drafts.

Additional file 5: Table S4. Bacterial species or subspecies with technological beneficial use in food products listed by Bourdichon and coworkers (2012).

Additional file 6: Figure S1. Global phylogeny of 179 Firmicutes bacterial isolates, including 42 genomes from our project.

Additional file 7: Figure S2. Global phylogeny of 14 Bacteroidetes bacterial isolates, including 6 genomes from our project.

Additional file 8: Figure S3. Global phylogeny of 180 Proteobacteria bacterial isolates, including 50 genomes from our project.

Additional file 9: Figure S4. Global phylogeny of 84 Actinobacteria bacterial isolates, including 32 genomes from our project.

Additional file 10: Table S5. List of the genomes used for phylogenetic and metagenomic analyses.

Additional file 11: Table S6. Proteins involved in the catabolism of D-galactonate in Arthrobacter strains.

Additional file 12: Table S7. Genomic comparison of four Streptococcus infantarius subsp. infantarius strains.

Additional file 13: Figure S5. Phylogeny of 14 LacZ proteins from Streptococcus strains.

Additional file 14: Table S8. Mapping of the sequencing reads from the metagenomic analysis of the cheese samples.

Additional file 15: Table S9. Mapping of the sequencing reads from genomic analysis of already sequenced genome to assess the average level of reads that could not be mapped inherent to SOLiD technology.

Additional file 16: Figure S6. Mean quality distribution of the reads from the metagenomic analysis of the cheese samples.

\section{Competing interests}

The authors declare that they have no competing interests.

\section{Authors' contributions}

PR and MA managed the project and designed the analysis. Fl, AH, CD and M-CM performed microbiogical work. AH and FI processed DNA pools. SK and SDE managed DNA clustering pools sequencing. J-MB, PL and NP supervised computing facilities. SR realized optimized draft assembly. $V L$ contributed to genome annotation and submission. MA, PR, A-LA, SR, NP, AH, FI, CM, CD and $\mathrm{M}-\mathrm{CM}$ performed the data analysis. MA, PR, FI, CM, AH, CD and MP wrote the paper. All authors read and approved the final manuscript.

\section{Acknowledgements}

M.A. was supported by a grant from the Ministère de la Recherche et de I'Education Nationale (France). This work was mainly supported by the ANR grant "Food Microbiomes" (ANR-08-ALIA-007-02) coordinated by P.R. and additional funding from the Centre National Interprofessionnel de I'Economie Laitière (France). Computing was facilitated by the funds obtained from the OpenGPU FUI collaborative research projects, with funding from DGCIS. Optimized re-assembly draft has been processed with
CBS computing facility (Denmark). We thank Junjie Qin for the experimental advices on the pool preparations, Cécile Callon for her help for strain cultivation and DNA extraction, and Henrik Bjørn Nielsen for discussion on co-abundance clustering methods. We also thank Serge Casaregola and Joëlle Dupont for providing an early access to the genomes of Geotrichum candidum CLIB 918, Penicillium roqueforti FM 164 and Penicillium camemberti FM 013. We finally thank Antoine Hermet and Jérôme Mounier for the cheese metagenomic DNA extraction.

\section{Author details}

${ }^{1}$ Institut National de la Recherche Agronomique, UMR 1319 MICALIS, 78352 Jouy-en-Josas, France. ${ }^{2}$ AgroParisTech, UMR MICALIS, 78352 Jouy-en-Josas, France. ${ }^{3}$ Institut National de la Recherche Agronomique, US 1367 MGP, 78352 Jouy-en-Josas, France. ${ }^{4}$ AgroParisTech, UMR 782 GMPA, 78850 Thiverval-Grignon, France. ${ }^{5}$ Center for Biological Sequence Analysis, Technical University of Denmark, DK-2800 Kongens Lyngby, Denmark. ${ }^{6}$ Institut National de la Recherche Agronomique, UMR 782 GMPA, 78850 Thiverval-Grignon, France. ${ }^{7}$ Institut National de la Recherche Agronomique, UR 545 URF, 15000 Aurillac, France. ${ }^{8}$ Institut National de la Recherche Agronomique, UR 1077 MIG, 78352 Jouy-en-Josas, France. ${ }^{9}$ Department of Computer Science, Center for Bioinformatics and Computational Biology, University of Maryland, College Park, MD 20742, USA.

Received: 20 June 2014 Accepted: 4 December 2014 Published: 13 December 2014

\section{References}

1. Feurer C, Irlinger F, Spinnler HE, Glaser P, Vallaeys T: Assessment of the rind microbial diversity in a farmhouse-produced vs a pasteurized industrially produced soft red-smear cheese using both cultivation and rDNA-based methods. J Appl Microbiol 2004, 97:546-556.

2. Rea MC, Görges S, Gelsomino R, Brennan NM, Mounier J, Vancanneyt M, Scherer S, Swings J, Cogan TM: Stability of the biodiversity of the surface consortia of Gubbeen, a red-smear cheese. J Dairy Sci 2007, 90:2200-2210.

3. Goerges S, Mounier J, Rea MC, Gelsomino R, Heise V, Beduhn R, Cogan TM Vancanneyt M, Scherer S: Commercial ripening starter microorganisms inoculated into cheese milk do not successfully establish themselves in the resident microbial ripening consortia of a South German red smear cheese. Appl Environ Microbiol 2008, 74:2210-2217.

4. Larpin-Laborde S, Imran M: Surface microbial consortia from Livarot, a French smear-ripened cheese. Can J Microbiol 2011, 660:651-660.

5. Feutry F, Oneca M, Berthier F, Torre P: Biodiversity and growth dynamics of lactic acid bacteria in artisanal PDO Ossau-Iraty cheeses made from raw ewe's milk with different starters. Food Microbiol 2012, 29:33-42.

6. Montel MC, Buchin S, Mallet A, Delbes-Paus C, Vuitton DA, Desmasures N, Berthier F: Traditional cheeses: rich and diverse microbiota with associated benefits. Int J Food Microbiol 2014, 177:136-154.

7. Delbès C, Ali-Mandjee L, Montel M-C: Monitoring bacterial communities in raw milk and cheese by culture-dependent and -independent $16 \mathrm{~S}$ rRNA gene-based analyses. Appl Environ Microbiol 2007, 73:1882-1891.

8. Feurer C, Vallaeys T, Corrieu G, Irlinger F: Does smearing inoculum reflect the bacterial composition of the smear at the end of the ripening of $a$ French soft, red-smear cheese? J Dairy Sci 2004, 87:3189-3197.

9. Mounier J, Monnet C, Jacques N, Antoinette A, Irlinger F: Assessment of the microbial diversity at the surface of Livarot cheese using culture-dependent and independent approaches. Int J Food Microbiol 2009, 133:31-37.

10. Bourdichon F, Casaregola S, Farrokh C, Frisvad JC, Gerds ML, Hammes WP Harnett J, Huys G, Laulund S, Ouwehand A, Powell IB, Prajapati JB, Seto Y, Ter Schure E, Van Boven A, Vankerckhoven V, Zgoda A, Tuijtelaars S, Hansen EB: Food fermentations: microorganisms with technological beneficial use. Int J Food Microbiol 2012, 154:87-97.

11. Roth E, Miescher Schwenninger S, Hasler M, Eugster-Meier E, Lacroix C: Population dynamics of two antilisterial cheese surface consortia revealed by temporal temperature gradient gel electrophoresis. BMC Microbiol 2010, 10:74.

12. Ishikawa M, Kodama K, Yasuda H, Okamoto-Kainuma A, Koizumi K, Yamasato K. Presence of halophilic and alkaliphilic lactic acid bacteria in various cheeses. Lett App/ Microbio/ 2007, 44:308-313.

13. Masoud W, Vogensen FK, Lillevang S, Abu Al-Soud W, Sørensen SJ, Jakobsen $\mathrm{M}$ : The fate of indigenous microbiota, starter cultures, Escherichia coli, Listeria innocua and Staphylococcus aureus in Danish raw milk and 
cheeses determined by pyrosequencing and quantitative real time (qRT)-PCR. Int J Food Microbiol 2012, 153:192-202.

14. Brennan NM, Brown R, Goodfellow M, Ward AC, Beresford TP, Vancanneyt $M$, Cogan TM, Fox PF: Microbacterium gubbeenense sp. nov., from the surface of a smear-ripened cheese. Int J Syst Evol Microbiol 2001, 51(Pt 6):1969-1976.

15. Irlinger F, Bimet F, Delettre J, Lefèvre M, Grimont PAD: Arthrobacter bergerei sp. nov. and Arthrobacter arilaitensis sp. nov., novel coryneform species isolated from the surfaces of cheeses. Int J Syst Evol Microbiol 2005, 55(Pt 1):457-462.

16. Bora N, Vancanneyt M, Gelsomino R, Swings J, Brennan N, Cogan TM, Larpin S, Desmasures N, Lechner FE, Kroppenstedt RM, Ward AC, Goodfellow M: Agrococcus casei sp. nov., isolated from the surfaces of smear-ripened cheeses. Int J Syst Evol Microbiol 2007, 57(Pt 1):92-97.

17. Bleicher A, Neuhaus K, Scherer S: Vibrio casei sp. nov., isolated from the surfaces of two French red smear soft cheeses. Int J Syst Evol Microbiol 2010, 60 (Pt 8):1745-1749.

18. Didienne R, Defargues C, Callon C, Meylheuc T, Hulin S, Montel M-C: Characteristics of microbial biofilm on wooden vats ('gerles') in PDO Salers cheese. Int J Food Microbiol 2012, 156:91-101.

19. Verdier-Metz I, Gagne G, Bornes S, Monsallier F, Veisseire P, Delbès-Paus C, Montel M-C: Cow teat skin, a potential source of diverse microbial populations for cheese production. Appl Environ Microbiol 2012, 78:326-333.

20. Monnet C, Loux V, Gibrat J-F, Spinnler E, Barbe V, Vacherie B, Gavory F, Gourbeyre E, Siguier P, Chandler M, Elleuch R, Irlinger F, Vallaeys T: The Arthrobacter arilaitensis Re117 genome sequence reveals its genetic adaptation to the surface of cheese. PLoS One 2010, 5:14.

21. Falentin H, Deutsch S-M, Jan G, Loux V, Thierry A, Parayre S, Maillard M-B, Dherbécourt J, Cousin FJ, Jardin J, Siguier P, Couloux A, Barbe V, Vacherie B, Wincker P, Gibrat J-F, Gaillardin C, Lortal S: The complete genome of Propionibacterium freudenreichii CIRM-BIA1, a hardy actinobacterium with food and probiotic applications. PLoS One 2010, 5:e11748.

22. Schröder J, Maus I, Trost E, Tauch A: Complete genome sequence of Corynebacterium variabile DSM 44702 isolated from the surface of smear-ripened cheeses and insights into cheese ripening and flavor generation. BMC Genomics 2011, 12:545

23. Makarova K, Slesarev A, Wolf Y, Sorokin A, Mirkin B, Koonin E, Pavlov A, Pavlova N, Karamychev V, Polouchine N, Shakhova V, Grigoriev I, Lou Y, Rohksar D, Lucas S, Huang K, Goodstein DM, Hawkins T, Plengvidhya V, Welker D, Hughes J, Goh Y, Benson A, Baldwin K, Lee JH, Diaz-Muniz I, Dosti B, Smeianov V, Wechter W, Barabote R, et al: Comparative genomics of the lactic acid bacteria. Proc Natl Acad Sci U S A 2006.

24. Sjöling S, Cowan D: Metagenomics: microbial community genomes revealed. In Psychrophiles from Biodivers to Biotechnol. 2008:313-332.

25. Kullen MJ, Sanozky-Dawes RB, Crowell DC, Klaenhammer TR: Use of the DNA sequence of variable regions of the 16S rRNA gene for rapid and accurate identification of bacteria in the Lactobacillus acidophilus complex. J Appl Microbiol 2000, 89:511-516.

26. Ercolini D: High-throughput sequencing and metagenomics: steps ahead in the culture-independent analysis of food microbial ecology. Appl Environ Microbiol 2013

27. Ercolini D: High-throughput sequencing and metagenomics: moving forward in the culture-independent analysis of food microbial ecology. Appl Environ Microbiol 2013, 79:3148-3155.

28. Bokulich NA, Mills DA: Facility-specific "house" microbiome drives microbial landscapes of artisan cheesemaking plants. Appl Environ Microbiol 2013, 79:5214-5223.

29. Lusk TS, Ottesen AR, White JR, Allard MW, Brown EW, Kase JA: Characterization of microflora in Latin-style cheeses by next-generation sequencing technology. BMC Microbiol 2012, 12:254.

30. Ercolini D, De Filippis F, La Storia A, lacono M: "Remake" by highthroughput sequencing of the microbiota involved in the production of water buffalo mozzarella cheese. Appl Environ Microbiol 2012, 78:8142-8145.

31. Quigley L, O'Sullivan O, Beresford TP, Ross RP, Fitzgerald GF, Cotter PD: High-throughput sequencing for detection of subpopulations of bacteria not previously associated with artisanal cheeses. Appl Environ Microbiol 2012, 78:5717-5723

32. Abubucker S, Segata N, Goll J, Schubert AM, Izard J, Cantarel BL, RodriguezMueller B, Zucker J, Thiagarajan M, Henrissat B, White O, Kelley ST, Methé B, Schloss PD, Gevers D, Mitreva M, Huttenhower C: Metabolic reconstruction for metagenomic data and its application to the human microbiome. PLoS Comput Biol 2012, 8:e1002358.

33. Wolfe BE, Button JE, Santarelli M, Dutton RJ: Cheese rind communities provide tractable systems for in situ and in vitro studies of microbial diversity. Cell 2014, 158:422-433.

34. Huson D, Mitra S, Ruscheweyh H: Integrative analysis of environmental sequences using MEGAN4. Genome Res 2011, 21:1552-1560.

35. Nielsen HB, Almeida M, Juncker AS, Rasmussen S, Li J, Sunagawa S, Plichta DR, Gautier L, Pedersen AG, Le Chatelier E, Pelletier E, Bonde I, Nielsen T, Manichanh C, Arumugam M, Batto J-M, Quintanilha Dos Santos MB, Blom N, Borruel N, Burgdorf KS, Boumezbeur F, Casellas F, Doré J, Dworzynski P, Guarner F, Hansen T, Hildebrand F, Kaas RS, Kennedy S, Kristiansen K, et al: Identification and assembly of genomes and genetic elements in complex metagenomic samples without using reference genomes. Nat Biotechnol 2014, 32:822-828.

36. Le Chatelier E, Nielsen T, Qin J, Prifti E, Hildebrand F, Falony G, Almeida M, Arumugam M, Batto J-M, Kennedy S, Leonard P, Li J, Burgdorf K, Grarup N, Jørgensen T, Brandslund I, Nielsen HB, Juncker AS, Bertalan M, Levenez F, Pons N, Rasmussen S, Sunagawa S, Tap J, Tims S, Zoetendal EG, Brunak S, Clément K, Doré J, Kleerebezem M, et al: Richness of human gut microbiome correlates with metabolic markers. Nature 2013, 500:541-546.

37. Altschul S, Gish W, Miller W: Basic local alignment search tool. J Mol Biol 1990, 215:403-410.

38. Human Microbiome Jumpstart Reference Strains Consortium, Nelson KE, Weinstock GM, Highlander SK, Worley KC, Creasy HH, Wortman JR, Rusch DB, Mitreva M, Sodergren E, Chinwalla AT, Feldgarden M, Gevers D, Haas BJ, Madupu R, Ward DV, Birren BW, Gibbs RA, Methe B, Petrosino JF, Strausberg RL, Sutton GG, White OR, Wilson RK, Durkin S, Giglio MG, Gujja S, Howarth $C$, Kodira CD, Kyrpides N, et al: A catalog of reference genomes from the human microbiome. Science 2010, 328(5981):994-999.

39. Callister SJ, McCue LA, Turse JE, Monroe ME, Auberry KJ, Smith RD, Adkins JN, Lipton MS: Comparative bacterial proteomics: analysis of the core genome concept. PLoS One 2008, 3:e1542

40. Mende DR, Sunagawa S, Zeller G, Bork P: Accurate and universal delineation of prokaryotic species. Nat Methods 2013, 10:881-884.

41. Crocker FH, Fredrickson JK, White DC, Ringelberg DB, Balkwill DL: Phylogenetic and physiological diversity of Arthrobacter strains isolated from unconsolidated subsurface sediments. Microbiology 2000, 146(Pt 6):1295-1310.

42. Jans C, Follador R, Hochstrasser M, Lacroix C, Meile L, Stevens MJA: Comparative genome analysis of Streptococcus infantarius subsp. infantarius CJ18, an African fermented camel milk isolate with adaptations to dairy environment. BMC Genomics 2013, 14:200.

43. Jans C, Gerber A, Bugnard J, Njage PMK, Lacroix C, Meile L: Novel Streptococcus infantarius subsp. infantarius variants harboring lactose metabolism genes homologous to Streptococcus thermophilus. Food Microbiol 2012, 31:33-42.

44. Csurös M, Milosavljevic A: Pooled genomic indexing (PGI): analysis and design of experiments. J Comput Biol 2004, 11:1001-1021.

45. Aird D, Ross MG, Chen W-S, Danielsson M, Fennell T, Russ C, Jaffe DB, Nusbaum C, Gnirke A: Analyzing and minimizing PCR amplification bias in Illumina sequencing libraries. Genome Biol 2011, 12:R18.

46. Vianna PCB, Mazal G, Santos MV, Bolini HMA, Gigante ML: Microbial and sensory changes throughout the ripening of Prato cheese made from milk with different levels of somatic cells. J Dairy Sci 2008, 91:1743-1750.

47. Jaeggi JJ, Govindasamy-Lucey S, Berger YM, Johnson ME, McKusick BC, Thomas DL, Wendorff WL: Hard ewe's milk cheese manufactured from milk of three different groups of somatic cell counts. J Dairy Sci 2003, 86:3082-3089.

48. Meslier V, Loux V, Renault P: Genome sequence of Leuconostoc pseudomesenteroides strain 4882 , isolated from a dairy starter culture. J Bacteriol 2012, 194:6637.

49. Maoz A, Mayr R, Scherer S: Temporal stability and biodiversity of two complex antilisterial cheese-ripening microbial consortia. Appl Environ Microbiol 2003, 69:4012-4018

50. Ogier J, Lafarge $V$, Girard V: Molecular fingerprinting of dairy microbial ecosystems by use of temporal temperature and denaturing gradient gel electrophoresis. Appl Environ Microbiol 2004, 70:5628-5643.

51. Fontana C, Cappa F, Rebecchi A, Cocconcelli PS: Surface microbiota analysis of Taleggio, Gorgonzola, Casera, Scimudin and Formaggio di Fossa Italian cheeses. Int J Food Microbiol 2010, 138:205-211. 
52. Bockelmann W, Willems KP, Neve H, Heller KH: Cultures for the ripening of smear cheeses. Int Dairy J 2005, 15:719-732.

53. Mounier J, Gelsomino R: Surface microflora of four smear-ripened cheeses. Appl Env Microbiol 2005, 71:6489-6500.

54. Edwards U, Rogall T, Blöcker H: Isolation and direct complete nucleotide determination of entire genes: characterization of a gene coding for $16 \mathrm{~S}$ ribosomal RNA. Nucleic Acids Res 1989, 17:7843-7853.

55. Adékambi T, Drancourt M, Raoult D: The rpoB gene as a tool for clinical microbiologists. Trends Microbiol 2009, 17:37-45.

56. Tayeb LA, Lefevre M, Passet V, Diancourt L, Brisse S, Grimont PAD: Comparative phylogenies of Burkholderia, Ralstonia, Comamonas, Brevundimonas and related organisms derived from rpoB, gyrB and rrs gene sequences. Res Microbiol 2008, 159:169-177.

57. Huang X, Madan A: CAP3: A DNA sequence assembly program. Genome Res 1999, 9:868-877

58. Luo R, Liu B, Xie Y, Li Z, Huang W, Yuan J, He G, Chen Y, Pan Q, Liu Y, Tang J, Wu G, Zhang H, Shi Y, Liu Y, Yu C, Wang B, Lu Y, Han C, Cheung DW, Yiu S-M, Peng S, Xiaogian Z, Liu G, Liao X, Li Y, Yang H, Wang J, Lam T-W, Wang J: SOAPdenovo2: an empirically improved memory-efficient short-read de novo assembler. Gigascience 2012, 1:18.

59. McCallum A, Nigam K, Ungar L: Efficient Clustering of High-Dimensional Data Sets With Application to Reference Matching, Proceedings of the sixth ACM SIGKDD international conference on Knowledge discovery and data mining. 2000:169-178.

60. Langmead B, Trapnell C, Pop M, Salzberg SL: Ultrafast and memoryefficient alignment of short DNA sequences to the human genome. Genome Biol 2009, 10:R25.

61. Li H, Durbin R: Fast and accurate short read alignment with BurrowsWheeler transform. Bioinformatics 2009, 25:1754-1760.

62. Kelley D, Schatz M, Salzberg S: Quake: quality-aware detection and correction of sequencing errors. Genome Biol 2010, 11:R116.

63. Zerbino DR, Birney E: Velvet: algorithms for de novo short read assembly using de Bruijn graphs. Genome Res 2008, 18:821-829.

64. Chain P, Grafham D, Fulton R: Genome project standards in a new era of sequencing. Science 2009, 326(5950):236-237.

65. Aziz RK, Bartels D, Best AA, Dejongh M, Disz T, Edwards RA, Formsma K, Gerdes S, Glass EM, Kubal M, Meyer F, Olsen GJ, Olson R, Osterman AL, Overbeek RA, McNeil LK, Paarmann D, Paczian T, Parrello B, Pusch GD, Reich C, Stevens R, Vassieva O, Vonstein V, Wilke A, Zagnitko O: The RAST Server: rapid annotations using subsystems technology. BMC Genomics 2008, 9:75

66. Edgar RC: MUSCLE: multiple sequence alignment with high accuracy and high throughput. Nucleic Acids Res 2004, 32:1792-1797.

67. Price $M$, Dehal P, Arkin A: FastTree 2-approximately maximum-likelihood trees for large alignments. PLoS One 2010, 5:e9490.

68. Letunic I, Bork P: Interactive tree of life v2: online annotation and display of phylogenetic trees made easy. Nucleic Acids Res 2011, 39:W475-W478.

doi:10.1186/1471-2164-15-1101

Cite this article as: Almeida et al:: Construction of a dairy microbial genome catalog opens new perspectives for the metagenomic analysis of dairy fermented products. BMC Genomics 2014 15:1101.

\section{Submit your next manuscript to BioMed Central and take full advantage of:}

- Convenient online submission

- Thorough peer review

- No space constraints or color figure charges

- Immediate publication on acceptance

- Inclusion in PubMed, CAS, Scopus and Google Scholar

- Research which is freely available for redistribution

Submit your manuscript at www.biomedcentral.com/submit
( Biomed Central 